OPEN ACCESS

Edited by:

Chen Chen

Central South University, China

Reviewed by:

Diego Signorelli,

Niguarda Ca 'Granda Hospital, Italy

Rafael Lopez Castro,

Hospital Clínico Universitario de

Valladolid, Spain

${ }^{*}$ Correspondence:

Morihito Okada

morihito@hiroshima-u.ac.jp

Specialty section: This article was submitted to

Thoracic Oncology, a section of the journal

Frontiers in Oncology

Received: 29 October 2020 Accepted: 06 May 2021 Published: 07 June 2021

Citation:

Tsutani $Y$, Shimada $Y$, Ito $H$

Miyata Y, Ikeda N, Nakayama H

and Okada M (2021) Identification of High-Risk of Recurrence in Clinical Stage I Non-Small Cell Lung Cancer.

Front. Oncol. 11:622742.

doi: 10.3389/fonc.2021.622742

\section{Identification of High-Risk of Recurrence in Clinical Stage I Non-Small Cell Lung Cancer}

\author{
Yasuhiro Tsutani ${ }^{1}$, Yoshihisa Shimada ${ }^{2}$, Hiroyuki Ito $^{3}$, Yoshihiro Miyata ${ }^{1}$, Norihiko Ikeda ${ }^{2}$ \\ Haruhiko Nakayama ${ }^{3}$ and Morihito Okada ${ }^{1 *}$ \\ ${ }^{1}$ Department of Surgical Oncology, Hiroshima University, Hiroshima, Japan, ${ }^{2}$ Department of Thoracic Surgery, Tokyo \\ Medical University, Tokyo, Japan, ${ }^{3}$ Department of Thoracic Surgery, Kanagawa Cancer Center, Yokohama, Japan
}

Objective: This study aimed to identify patients at a high risk of recurrence using preoperative high-resolution computed tomography (HRCT) in clinical stage I non-small cell lung cancer (NSCLC).

Methods: A total of 567 patients who underwent screening and 1,216 who underwent external validation for clinical stage I NSCLC underwent lobectomy or segmentectomy. Staging was used on the basis of the $8^{\text {th }}$ edition of the tumor-node-metastasis classification. Recurrence-free survival (RFS) was estimated using the Kaplan-Meier method, and the multivariable Cox proportional hazards model was used to identify independent prognostic factors for RFS.

Results: A multivariable Cox analysis identified solid component size (hazard ratio [HR], 1.66; 95\% confidence interval $[\mathrm{Cl}] 1.30-2.12 ; \mathrm{P}<0.001)$ and pure solid type $(\mathrm{HR}, 1.82$; 95\% $\mathrm{Cl} 1.11-2.96 ; \mathrm{P}=0.017$ ) on HRCT findings as independent prognostic factors for RFS. When patients were divided into high-risk ( $n=331$; solid component size of $>2 \mathrm{~cm}$ or pure solid type) and low-risk ( $n=236$; solid component size of $\leq 2 \mathrm{~cm}$ and part solid type) groups, there was a significant difference in RFS (HR, 5.33; 95\% Cl 3.09-9.19; 5-year RFS, $69.8 \%$ vs. 92.9\%, respectively; $P<0.001)$. This was confirmed in the validation set (HR, 5.32; 95\% Cl 3.61-7.85; 5-year RFS, 72.0\% vs. 94.8\%, respectively; $P<0.001)$.

Conclusions: In clinical stage I NSCLC, patients with a solid component size of $>2 \mathrm{~cm}$ or pure solid type on HRCT were at a high risk of recurrence.

Keywords: ground-glass opacity, high-resolution computed tomography, recurrence, non-small cell lung cancer, solid component size

\section{INTRODUCTION}

Early-stage non-small cell lung cancer (NSCLC) is frequently detected using more complex procedure, such as high-resolution computed tomography (HRCT) and widespread use of low-dose helical computed tomography (CT) for tumor screening $(1,2)$. The occasion to treat patients with earlystage NSCLC has increased, and pulmonary resection plays a main role in such treatment. Complete resection would be expected to lead a good prognosis for stage I NSCLC. However, complete resection does not always ensure the cure of disease and the 5 -year disease-free survival rate for stage IA NSCLC is $84.3 \%$ and for stage IB NSCLC is $65.8 \%$ (3). 
Although the tumor-node-metastasis (TNM) classification can stratify patients into different prognostic groups, stage I NSCLC is considered to be a heterogeneous group. Therefore, useful parameters are needed to predict postoperative recurrence when deciding on treatment strategies, such as the application of sublobar resection and additional perioperative systemic therapy. A high maximum standardized uptake value (SUVmax) with [18F]-fluoro2-deoxy-D-glucose (FDG) positron emission tomography (PET)/ $\mathrm{CT}$ reflects tumor invasiveness and has a negative impact on prognosis in patients with resected early-stage NSCLC $(2,4)$. However, because imaging protocols, equipment, and measurement methods vary between institutions, the optimal SUVmax cutoff value also differs by institution and between studies. Therefore, using FDG-PET/CT as a prognostic factor in a universal setting is challenging at present.

One of the important proposals in the $8^{\text {th }}$ edition of the $\mathrm{T}$ classification of lung cancer is the size of the solid component excluding ground-glass opacity (GGO) to classify clinical $\mathrm{T}$ factors $(5,6)$. In the present study, we aimed to identify patients at a high risk of postoperative recurrence in clinical stage I NSCLC using preoperative HRCT, which is a globally applicable method. High-risk patients may be candidates for neoadjuvant therapy even in clinical stage I NSCLC. The primary endpoint of this study was recurrence-free survival (RFS).

\section{MATERIALS AND METHODS}

\section{Patients}

As the screening set, a total of 567 consecutive patients with clinical stage I NSCLC who underwent lobectomy or segmentectomy with systematic lymph node dissection at Hiroshima University between January $1^{\text {st }} 2010$ and December $31^{\text {st }} 2016$ were enrolled. All patients were staged according to the TNM Classification of Malignant Tumors, $8^{\text {th }}$ edition (7). Endobronchial ultrasonography and mediastinoscopy were not routinely performed. Lymph node metastasis was determined as negative when swollen mediastinal or hilar lymph nodes measuring short axis of $>$ $1 \mathrm{~cm}$ were not evident on HRCT, and FDG did not accumulate an SUXmax of $>1.5$ in these lymph nodes according to FDGPET. The inclusion criteria included preoperative staging determined by HRCT and FDG-PET/CT and curative surgery with lobectomy or segmentectomy without induction therapy. The screening set of patients formed the high-risk group for recurrence. To externally validate the high-risk group, we used a combined cohort of two independent sets of 1,216 consecutive patients who underwent lobectomy or segmentectomy with systematic lymph node dissection (Tokyo Medical University and Kanagawa Cancer Center) between January $1^{\text {st }}, 2010$, and December $31^{\text {st }}, 2016$. The inclusion criteria were the same as those for the screening set (Figure 1).

The institutional review boards of the participating institutions approved this retrospective review, which was based on a prospective database, and waived the requirement for informed consent from individual patients (Kanagawa Cancer Center: February 28th, 2013; 24-KEN-54; Tokyo Medical University Hospital: February 25th, 2015; SH2969; Hiroshima University Hospital: June 13th, 2018; E-1216).

\section{HRCT}

Sixteen-row multidetector CT was used to obtain chest images independent of subsequent FDG-PET/CT examinations. For high-resolution tumor images, the following parameters were used: $120 \mathrm{kVp}, 200 \mathrm{~mA}, 1-2-\mathrm{mm}$ section thickness, $512 \times 512$ pixel resolution, $0.5-1.0$-s scan time, a high spatial reconstruction algorithm with a $20-\mathrm{cm}$ field of view, and mediastinal (level, 40 $\mathrm{HU}$; width, $400 \mathrm{HU}$ ) and lung (level, $-600 \mathrm{HU}$; width, $1600 \mathrm{HU}$ )

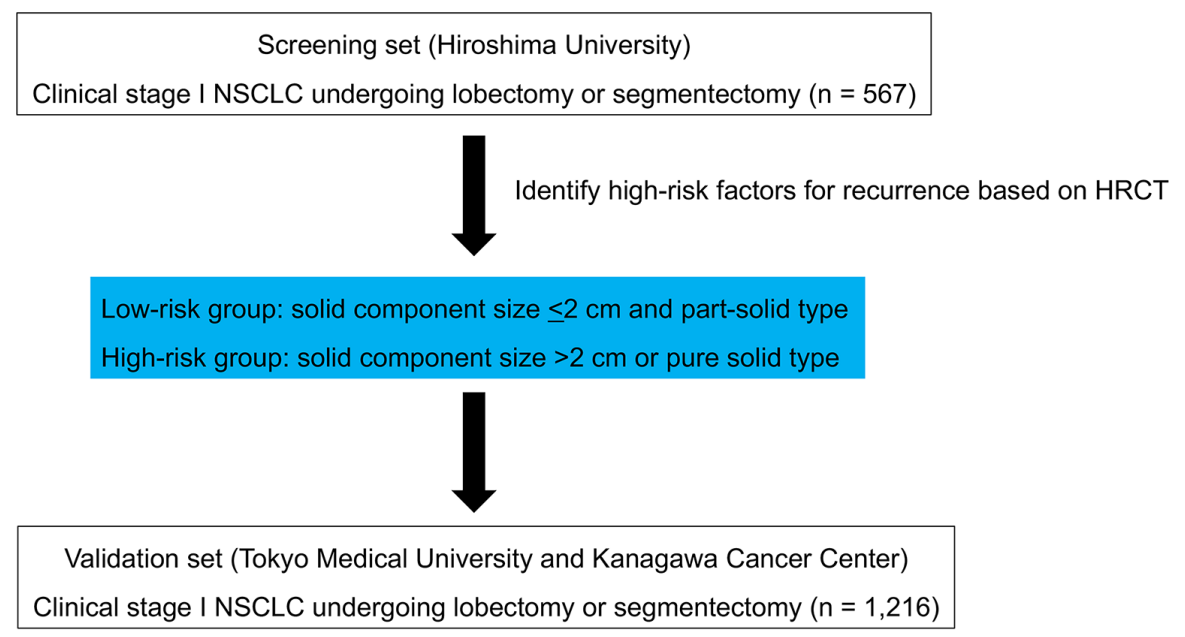

Confirm low-risk and high-risk group

FIGURE 1 | Scheme of the study. 
window settings. GGO was defined as a misty increase in lung attenuation without obscuring the underlying vascular markings. The size of the solid component of the tumor was defined as the maximum dimension of the solid component measured using lung window settings, excluding GGO (8). Pure solid tumor was defined as a tumor without GGO component. Part-solid tumor was defined as a tumor with GGO component. CT scans were reviewed and tumor sizes were determined by radiologists from each institution.

\section{Pathological Examination}

Tumor size was defined as the maximum dimension of the invasive tumor component, excluding the lepidic growth component described previously (9). Lymphatic and vascular invasion were assessed by immunohistochemistry with D2-40, which stains lymphatic ducts, and elastic Van Gieson staining of vessel elastic fibers. Lymphatic and vascular invasion were positive when penetration was detected as an extension of the malignant neoplasm. To evaluate pleural invasion, elastic tissue fibers were subject to elastic Van Gieson staining. Pleural invasion was defined as positive if cancer had invaded beyond the elastic layer, including invasion into the visceral pleural surface or neighboring organs. Histological examinations were determined by pathologists at each institution.

\section{Follow-Up Evaluation}

All patients who underwent lung resection were followed up from the day of surgery. Postoperative follow-up procedures, including a physical examination, chest roentgenogram every three months, and chest and abdominal CT examinations every six months, were performed for the first two years. Subsequently, a physical examination and chest roentgenogram were performed every six months, and a chest CT examination was performed every year.

\section{Statistical Analysis}

Data is presented as number (\%) or median and interquartile range (IQR) unless otherwise stated. The $\chi(2)$ test was used to compare the frequencies of categorical variables. Receiver operating characteristic curve of the solid component size for the prediction of recurrence were generated to determine the cutoff value that yielded optimal sensitivity and specificity. An independent-samples t-test was used to compare continuous variables. RFS was defined as the interval from the day of surgery until the first event (relapse or death from any cause) or right censoring on the day of final follow up. Overall survival (OS) was defined as the time from the day of surgery until death from any cause or right censoring at the day of final follow up. The Kaplan-Meier method was used to analyze RFS and OS. The log-rank test was used to assess differences in RFS and OS between groups. The multivariable Cox proportional hazards model was used to identify independent prognostic factors for RFS. The multivariable logistic regression analysis was used to identify independent predictive factors for lymph node metastasis. A P value of $<0.05$ was considered statistically significant. JMP 14.0 (SAS Institute, Cary, NC, USA) was used to statistically analyze the data.

\section{RESULTS}

\section{Screening Set}

Patient characteristics from the screening set $(n=567)$ are shown in Table 1.

A multivariable analysis revealed that age (hazard ratio [HR], 1.03; $\mathrm{P}=0.002)$, solid component size (HR, 1.66; $\mathrm{P}<0.001)$, and pure solid type $(\mathrm{HR}, 1.82 ; \mathrm{P}=0.017)$ were independent prognostic factors for RFS (Table 2). The optimal cutoff value of solid component size to predict recurrence was set as $2.0 \mathrm{~cm}$ from the receiver operating characteristic curve (Supplementary Figure 1).

A multivariable analysis revealed that age (odds ratio $[\mathrm{OR}]$, 1.03; $\mathrm{P}=0.002$ ), gender (male, OR, 1.67; $\mathrm{P}=0.013$ ), solid component size (OR, 1.75; $\mathrm{P}<0.001)$, pure solid type (OR, 2.85; $\mathrm{P}<0.001)$, and lobectomy $(\mathrm{OR}, 3.25 ; \mathrm{P}=0.001)$ were independent predictive factors for lymph node metastasis (Table 3).

There was a significant difference in RFS between patients with a solid component size of $\leq 2 \mathrm{~cm}$ ( $\mathrm{n}=363$; 5-year RFS, $88.1 \%)$ and those with a solid component size of $>2 \mathrm{~cm}(\mathrm{n}=204$; 5 -year RFS, 64.0\%; P $<0.0001$; Figure 2A). There was a significant difference in RFS between patients with part-solid tumors ( $\mathrm{n}=291$; 5 -year RFS, $89.5 \%$ ) and those with pure solid tumors ( $\mathrm{n}=276$; 5-year RFS, 68.8\%; $\mathrm{P}<0.0001$; Figure 2B). When patients were divided into four groups based on the solid component size and pure or part-solid type, RFS of patients with a solid component size of $\leq 2 \mathrm{~cm}$ with a part-solid tumor $(\mathrm{n}=$ 129) were favorable with a 5 -year RFS of $92.5 \%$. RFS in the other three groups was similar; 5-year RFS was $79.6 \%$ for patients with a solid component size of $\leq 2 \mathrm{~cm}$ with a pure solid tumor $(\mathrm{n}=$ 126), $75.9 \%$ for those with a solid component size of $>2 \mathrm{~cm}$ with a part solid tumor $(\mathrm{n}=54)$, and $58.9 \%$ for those with a solid component size of $>2 \mathrm{~cm}$ with a pure solid tumor $(\mathrm{n}=150$; Figure 2C). Based on these findings, we defined patients as at a low risk of recurrence with a solid component size of $<2 \mathrm{~cm}$ and part-solid type, and at a high risk of recurrence with a solid component size of $>2 \mathrm{~cm}$ or pure solid type. Pathological findings, such as histology; invasive component size; lymphatic, vascular and pleural invasion; and lymph node metastasis were significantly different between the low-risk and high-risk groups (Table 4). There was a significant difference in RFS between the low-risk ( $\mathrm{n}=236$; 5-year RFS, 92.9\%) and high-risk $(\mathrm{n}=331$; 5-year RFS, 69.8\%; HR, 5.33; P $<0.0001$; Figure 2D) groups. There was a significant difference in OS between the low-risk group ( $\mathrm{n}=236$; 5-year OS, 94.0\%) and the high-risk group $(\mathrm{n}=$ 331; 5-year OS, 80.4\%; HR, 3.81; P < 0.0001; Figure 2E).

\section{Validation Set}

The characteristics of patients in the validation set $(n=1,216)$ are shown in Table 1.

When patients were divided into the low risk of recurrence group $(n=553)$ and the high risk of recurrence group $(n=663)$, there were significant differences in pathological findings, such as histology; invasive component size; lymphatic, vascular, and pleural invasion; and lymph node metastasis between the two groups (Table 4). 
TABLE 1 | Patient characteristics in the screening set and validation set.

\begin{tabular}{|c|c|c|c|c|}
\hline & & Screening set $(n=567)$ & Validation set $(n=1,216)$ & $P$ value \\
\hline Age, median (IQR) & & $68(62-74)$ & $69(63-75)$ & 0.090 \\
\hline Gender & Male & 334 (58.9\%) & $603(49.6 \%)$ & $<0.001$ \\
\hline Smoking history & & $321(56.6 \%)$ & 657 (54.0\%) & 0.307 \\
\hline Solid component size (cm), median (IQR) & & $1.6(1.1-2.5)$ & $1.7(1.1-2.4)$ & 0.828 \\
\hline Pure solid type & & $276(48.7 \%)$ & $502(41.3 \%)$ & 0.003 \\
\hline \multirow[t]{3}{*}{ Histology } & Adenocarcinoma & $452(79.7 \%)$ & $1,033(85.0 \%)$ & 0.049 \\
\hline & Squamous cell carcinoma & $67(11.8 \%)$ & 109 (9.0\%) & \\
\hline & Others & $48(8.5 \%)$ & $73(6.0 \%)$ & \\
\hline \multirow[t]{2}{*}{ Procedure } & Lobectomy & $366(64.6 \%)$ & $1,060(87.2 \%)$ & $<0.001$ \\
\hline & Segmentectomy & $201(35.4 \%)$ & $156(12.8 \%)$ & \\
\hline Lymphatic invasion & & $111(19.6 \%)$ & 265 (21.8\%) & 0.283 \\
\hline Vascular invasion & & $140(24.7 \%)$ & 353 (29.0\%) & 0.055 \\
\hline Pleural invasion & & 87 (15.3\%) & 230 (18.9\%) & 0.064 \\
\hline Lymph node metastasis & & 47 (8.3\%) & $138(11.3 \%)$ & 0.045 \\
\hline \multirow[t]{9}{*}{ Pathological stage } & 0 & 20 (3.5\%) & $43(3.5 \%)$ & 0.002 \\
\hline & $\mid \mathrm{A} 1$ & $118(20.8 \%)$ & $350(28.8 \%)$ & \\
\hline & $\mathrm{IA} 2$ & $171(30.2 \%)$ & $321(26.4 \%)$ & \\
\hline & IA3 & $83(14.6 \%)$ & $130(10.7 \%)$ & \\
\hline & $\mathrm{IB}$ & 93 (16.4\%) & 179 (14.7\%) & \\
\hline & $\| A$ & 7 (1.2\%) & $16(1.3 \%)$ & \\
\hline & $\| \mathrm{B}$ & 51 (9.0\%) & $110(9.1 \%)$ & \\
\hline & $\| \mathrm{A} A$ & $24(4.2 \%)$ & $58(4.8 \%)$ & \\
\hline & IIIB & $0(0 \%)$ & $9(0.7 \%)$ & \\
\hline Adjuvant chemotherapy & Yes & 189 (33.3\%) & 240 & $<0.001$ \\
\hline
\end{tabular}

$I Q R$, interquartile range.

TABLE 2 | Multivariable analysis of recurrence-free survival.

\begin{tabular}{|c|c|c|c|c|c|c|c|}
\hline \multirow{2}{*}{$\begin{array}{l}\text { Screening set } \\
\text { Variable }\end{array}$} & & \multicolumn{3}{|c|}{ Univariable analysis } & \multicolumn{3}{|c|}{ Multivariable analysis } \\
\hline & & HR & $95 \% \mathrm{Cl}$ & $P$ value & HR & $95 \% \mathrm{Cl}$ & $P$ value \\
\hline Age & & 1.04 & $1.02-1.07$ & $<0.001$ & 1.03 & $1.01-1.05$ & 0.002 \\
\hline Gender & Male (vs. female) & 1.87 & $1.24-2.83$ & 0.003 & 1.07 & $0.63-1.83$ & 0.792 \\
\hline Smoking history & & 2.15 & $0.42-3.26$ & 0.001 & 1.48 & $0.84-2.61$ & 0.173 \\
\hline Solid component size (cm) & & 2.01 & $1.66-2.46$ & $<0.001$ & 1.66 & $1.30-2.12$ & $<0.001$ \\
\hline Pure solid type & & 3.31 & $2.17-5.04$ & $<0.001$ & 1.82 & $1.11-2.96$ & 0.017 \\
\hline Histology & Adenocarcinoma (vs. non-adenocarcinoma) & 0.39 & $0.26-0.58$ & $<0.001$ & 0.98 & $0.61-1.61$ & 0.915 \\
\hline Procedure & Lobectomy (vs. segmentectomy) & 1.46 & $0.95-2.24$ & 0.081 & 1.02 & $0.64-1.55$ & 0.944 \\
\hline
\end{tabular}

TABLE 3 | Multivariable analysis of lymph node metastasis.

\begin{tabular}{|c|c|c|c|c|c|c|c|}
\hline \multirow{2}{*}{$\begin{array}{l}\text { Screening set } \\
\text { Variable }\end{array}$} & & \multicolumn{3}{|c|}{ Univariable analysis } & \multicolumn{3}{|c|}{ Multivariable analysis } \\
\hline & & OR & $95 \% \mathrm{Cl}$ & $P$ value & OR & $95 \% \mathrm{Cl}$ & $P$ value \\
\hline Age & & 1.02 & $1.00-1.03$ & 0.033 & 1.03 & $1.01-1.04$ & 0.002 \\
\hline Gender & Male (vs. female) & 1.67 & $1.22-2.30$ & 0.001 & 1.67 & $1.11-2.50$ & 0.013 \\
\hline Smoking history & & 1.26 & $0.93-1.72$ & 0.136 & 0.67 & $0.44-1.02$ & 0.064 \\
\hline Solid component size $(\mathrm{cm})$ & & 2.21 & $1.97-2.61$ & $<0.001$ & 1.75 & $1.44-2.13$ & $<0.001$ \\
\hline Pure solid type & & 4.13 & $2.94-5.82$ & $<0.001$ & 2.85 & $1.94-4.20$ & $<0.001$ \\
\hline Histology & Adenocarcinoma (vs. non-adenocarcinoma) & 0.61 & $0.42-0.87$ & 0.009 & 1.28 & $0.84-1.95$ & 0.257 \\
\hline Procedure & Lobectomy (vs. segmentectomy) & 5.44 & $2.76-10.75$ & $<0.001$ & 3.25 & $1.61-6.56$ & 0.001 \\
\hline
\end{tabular}

There was a significant difference in RFS between the low-risk group (5-year RFS, 94.8\%) and high-risk group (5-year RFS, 72.0\%; HR, 5.32; P < 0.0001; Figure 3A). There was a significant difference in OS between the low-risk group (5-year OS, 95.7\%) and high-risk group (5-year OS, 84.2; HR, 3.54; P $<0.0001$; Figure 3B).

\section{DISCUSSION}

We identified patients at a high risk of recurrence using preoperative HRCT for clinical stage I NSCLC. Patients with a solid component size of $>2 \mathrm{~cm}$ or a pure solid tumor were at a high risk of recurrence. The HR values of RFS and OS in the 


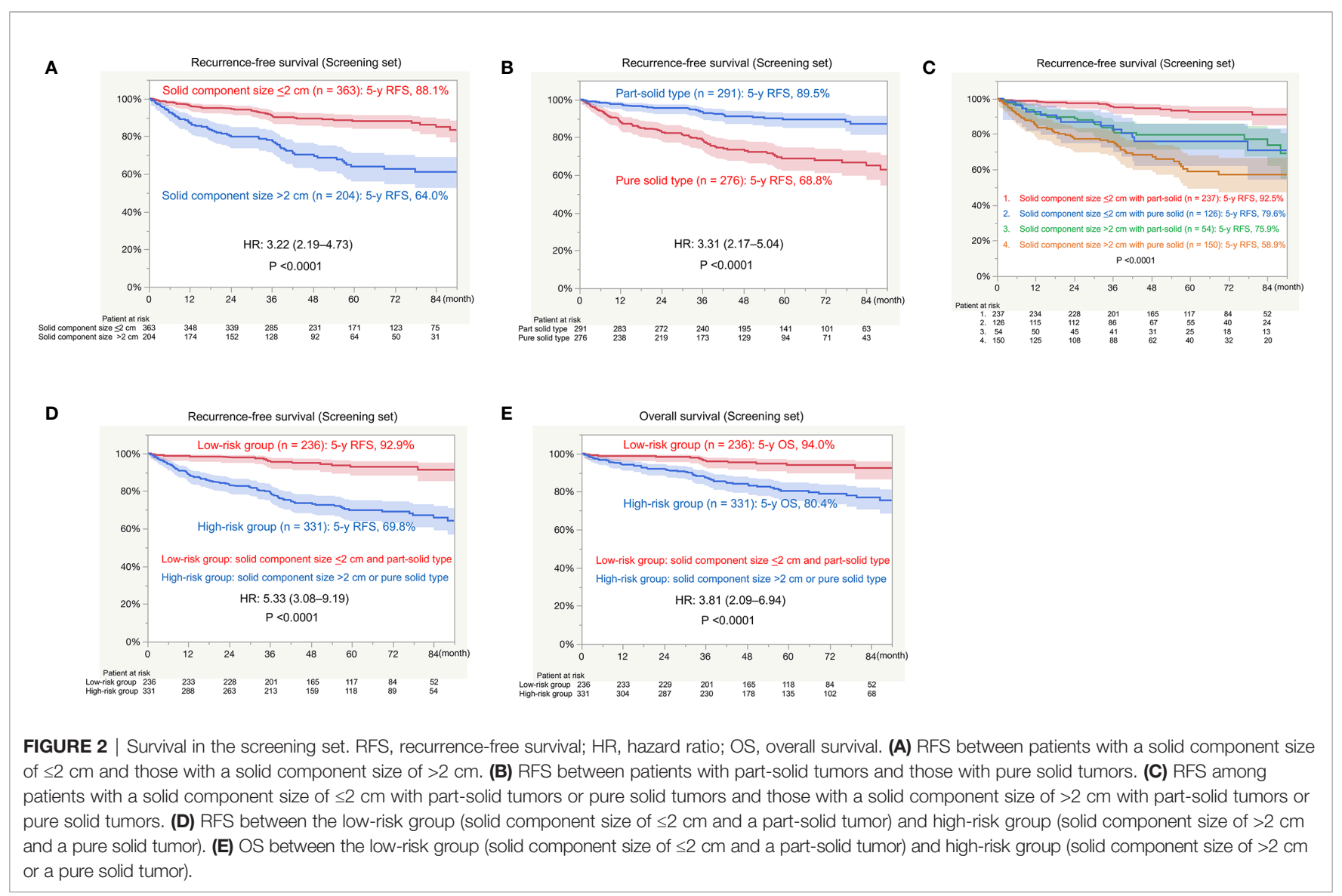

low-risk group in the screening set were 5.33 and 3.81 , respectively. These findings were confirmed in the external validation set with high concordance, with a HR of 5.32 for RFS and 3.54 for OS.
Several studies have reported the utility of solid component size to predict pathological tumor invasiveness and prognosis compared with whole tumor size $(8,10-12)$. As recommended in the $8^{\text {th }}$ edition of the $\mathrm{T}$ classification (6), using solid component

TABLE 4 | Comparison of pathological findings between low-risk and high-risk groups.

\begin{tabular}{|c|c|c|c|c|c|c|c|}
\hline & & \multicolumn{3}{|c|}{ Screening set } & \multicolumn{3}{|c|}{ Validation set } \\
\hline Histology & Adenocarcinoma & $234(99.2 \%)$ & 218 (65.9\%) & $<0.001$ & 539 (97.5\%) & $494(74.5 \%)$ & $<0.001$ \\
\hline & Squamous cell carcinoma & $1(0.42 \%)$ & $66(19.9 \%)$ & & $11(2.0 \%)$ & $98(14.8 \%)$ & \\
\hline & Others & $1(0.42 \%)$ & $47(14.2 \%)$ & & $3(0.5 \%)$ & $71(10.7 \%)$ & \\
\hline Invasive component size (cm) & & $1.1(0.6-1.8)$ & $2.0(1.5-2.9)$ & $<0.001$ & $0.8(0.3-1.4)$ & $2.0(1.5-2.8)$ & $<0.001$ \\
\hline Lymphatic invasion & & $13(5.5 \%)$ & 98 (29.6\%) & $<0.001$ & $45(8.1 \%)$ & 220 (33.2\%) & $<0.001$ \\
\hline Lymph node metastasis & & $0(0 \%)$ & 47 (14.2\%) & $<0.001$ & $18(3.3 \%)$ & $120(18.1 \%)$ & $<0.001$ \\
\hline \multirow[t]{5}{*}{ Pathological stage } & 0 & $20(8.5 \%)$ & $0(0 \%)$ & $<0.001$ & 38 (6.9\%) & $5(0.8 \%)$ & $<0.001$ \\
\hline & $\mid \mathrm{A} 1$ & 85 (36.0\%) & $33(10.0 \%)$ & & 287 (51.9\%) & $63(9.5 \%)$ & \\
\hline & $\mathrm{IA} 2$ & $83(35.2 \%)$ & $88(26.6 \%)$ & & $155(28.0 \%)$ & $166(25.0 \%)$ & \\
\hline & $\mathrm{IA3}$ & $22(9.3 \%)$ & $61(18.4 \%)$ & & $28(5.1 \%)$ & $102(15.4 \%)$ & \\
\hline & $\mathrm{IB}$ & $14(5.9 \%)$ & 79 (23.9\%) & & 22 (4.0\%) & $157(23.7 \%)$ & \\
\hline Adjuvant chemotherapy & Yes & $57(24.2 \%)$ & $132(39.9 \%)$ & $<0.001$ & $48(8.7 \%)$ & $192(29.0 \%)$ & $<0.001$ \\
\hline
\end{tabular}

$I Q R$, interquartile range. 
A

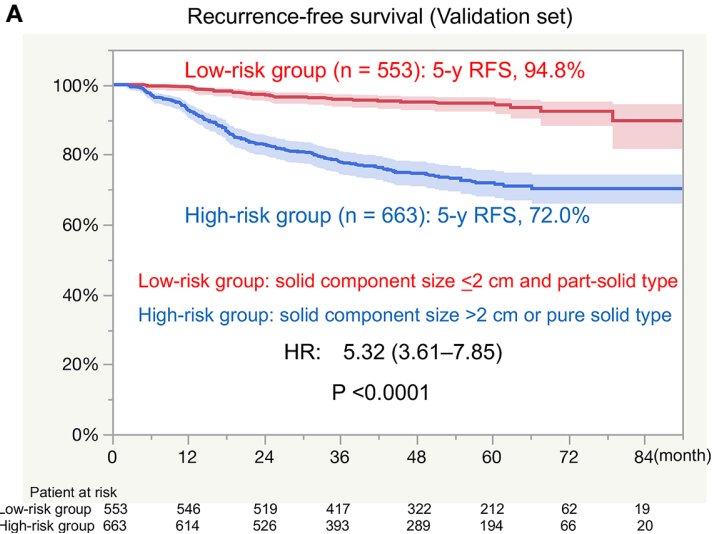

B

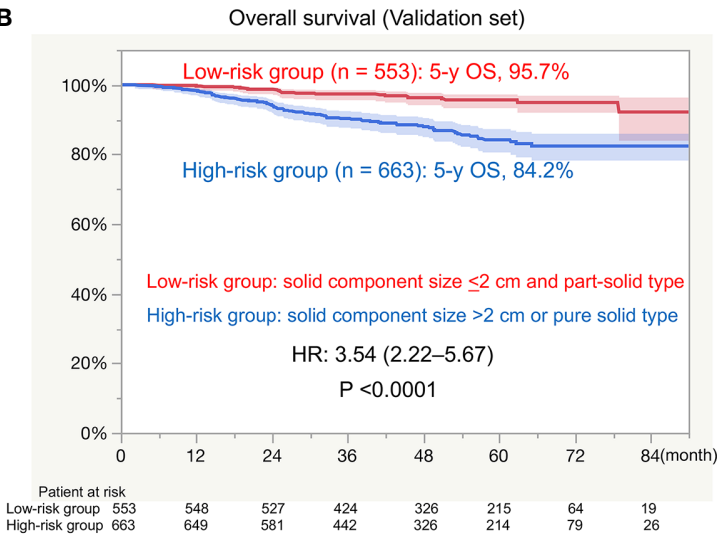

FIGURE 3 | Survival in the external validation set. RFS, recurrence-free survival; HR, hazard ratio; OS, overall survival. (A) RFS between the low-risk group (solid component size of $\leq 2 \mathrm{~cm}$ and a part-solid tumor) and high-risk group (solid component size of $>2 \mathrm{~cm}$ and a pure solid tumor). (B) OS between the low-risk group (solid component size of $\leq 2 \mathrm{~cm}$ and a part-solid tumor) and high-risk group (solid component size of $>2 \mathrm{~cm}$ and a pure solid tumor).

size as a prognostic factor seems to be reasonable from the results of the present study, which show that solid component size is an independent prognostic factor for RFS.

The presence of GGO was also reported as a prognostic factor in previous studies (13-15). The multivariable analysis of pure solid versus part-solid tumors showed this characteristic as an independent unfavorable prognostic factor for RFS, which is consistent with previous reports. Although survival after surgical resection for tumors with GGO was usually favorable (13-15), we need to pay attention to GGO tumors with a large solid component size. As shown in Figure 2C, RFS in patients with a part-solid tumor with a solid component size of $>2 \mathrm{~cm}$ is similar to that of pure solid tumors in this study. This finding was also supported by a previous study (16).

The group at a high risk of recurrence reflected the pathological findings in the current study. The frequency of non-adenocarcinoma histology; a larger invasive component size; lymphatic, vascular, and pleural invasion; and lymph node metastasis were significantly higher in the high-risk group compared with the low-risk group in both the screening and validation sets. In the multivariable analysis, solid component size and the pure solid type were proven to be predictive factors for lymph node metastasis. Patients at a high-risk of recurrence were also at high-risk of lymph node metastasis.

Preoperative prediction of the risk of postoperative recurrence is useful to decide treatment strategies. The excellent prognosis would be expected after lobectomy or segmentectomy with lymph node dissection in patients at a low risk of recurrence that show minimal malignant pathological findings in our study. There seems to be no role of neoadjuvant therapy in low-risk patients. However, when nodal metastasis is proven, adjuvant chemotherapy should be considered. In contrast, patients at a high risk of recurrence should undergo standard therapy, such as lobectomy with systematic lymph node dissection, because they potentially have lymph node metastasis with a probability of approximately $20 \%$. Although the use of perioperative adjuvant therapy for stage I NSCLC has not been established, additional systemic therapy, such as neoadjuvant chemotherapy or immunotherapy may be needed to improve outcomes in highrisk patients with stage I NSCLC. We are currently conducting a multicenter pilot study of neoadjuvant anti-programmed cell death-1 antibody for high-risk clinical stage I NSCLC with a solid component size of $>2 \mathrm{~cm}$ or pure solid type on HRCT (17).

The current study has some limitations. Only HRCT was used to predict risk factors for postoperative recurrence while several previous studies suggested that SUVmax on FDG-PET/CT was a promising predictor of prognosis $(2,4,10)$. Although no standardization of SUVmax on FDG-PET/CT in a global setting can be used at present, further studies should be done to elucidate the significance of FDG-PET using a novel standardization method, such as semiquantitative PET evaluation (18). Also, we did not routinely perform invasive mediastinal staging for node-negative tumors, although invasive staging is recommended for tumors $>3 \mathrm{~cm}$ (mainly adenocarcinoma with high FDG uptake) in the guideline (19). High-risk patients may also be candidates of invasive staging. Although we identified high-risk patients using preoperative HRCT findings to decide the application of neoadjuvant therapy, postoperative adjuvant therapy should be considered on the basis of pathological findings such as nodal involvement and pleural invasion.

In conclusion, we established patients at a high risk of recurrence using preoperative $\mathrm{HRCT}$ for clinical stage I NSCLC with high concordance HR in the external validation set. Patients with a solid component size of $>2 \mathrm{~cm}$ or pure solid tumors are potential candidates for perioperative systemic therapy to prevent postoperative recurrence.

\section{DATA AVAILABILITY STATEMENT}

The raw data supporting the conclusions of this article will be made available by the authors, without undue reservation. 


\section{ETHICS STATEMENT}

The studies involving human participants were reviewed and approved by Hiroshima University IRB, Kanagawa Cancer Center IRB, and Tokyo Medical University Hospital IRB. Written informed consent for participation was not required for this study in accordance with the national legislation and the institutional requirements.

\section{AUTHOR CONTRIBUTIONS}

YT: conceptualization, data curation, methodology, data analysis, and writing-original draft. YS: data collections, writing-review, and editing. HI: data collections, writingreview, and editing. YM: writing-review and editing. NI: writing-review and editing. $\mathrm{HN}$ : writing-review and editing. MO: writing-review and editing, supervision. All authors contributed to the article and approved the submitted version.

\section{REFERENCES}

1. Aberle DR, Adams AM, Berg CD, Black WC, Clapp JD, Fagerstrom RM, et al. Reduced Lung Cancer Mortality With Low-Dose Computed Tomographic Screening. N Engl J Med (2011) 365:395-409. doi: 10.1056/ NEJMoa1102873

2. Uehara H, Tsutani Y, Okumura S, Nakayama H, Adachi S, Yoshimura M, et al. Prognostic Role of Positron Emission Tomography and High-Resolution Computed Tomography in Clinical Stage IA Lung Adenocarcinoma. Ann Thorac Surg (2013) 96:1958-65. doi: 10.1016/j.athoracsur.2013.06.086

3. Okami J, Shintani Y, Okumura M, Ito H, Ohtsuka T, Toyooka S, et al. Demographics, Safety and Quality, and Prognostic Information in Both the Seventh and Eighth Editions of the TNM Classification in 18,973 Surgical Cases of the Japanese Joint Committee of Lung Cancer Registry Database in 2010. J Thorac Oncol (2019) 14:212-22. doi: 10.1016/j.jtho.2018.10.002

4. Nair VS, Barnett PG, Ananth L, Gould MK. Veterans Affairs Solitary Nodule Accuracy Project Cooperative Studies Group. PET Scan 18fFluorodeoxyglucose Uptake and Prognosis in Patients With Resected Clinical Stage IA Non-Small Cell Lung Cancer. Chest (2010) 137:1150-6. doi: 10.1378/chest.09-2356

5. Rami-Porta R, Bolejack V, Crowley J, Ball D, Kim J, Lyons G, et al. The IASLC Lung Cancer Staging Project: Proposals for the Revisions of the T Descriptors in the Forthcoming Eighth Edition of the TNM Classification for Lung Cancer. J Thorac Oncol (2015) 10:990-1003. doi: 10.1097/JTO.0000000000000559

6. Travis WD, Asamura H, Bankier AA, Beasley MB, Detterbeck F, Flieder DB, et al. The IASLC Lung Cancer Staging Project: Proposals for Coding T Categories for Subsolid Nodules and Assessment of Tumor Size in Part-Solid Tumors in the Forthcoming Eighth Edition of the TNM Classification of Lung Cancer. J Thorac Oncol (2016) 11:1204-23. doi: 10.1016/j.jtho.2016.03.025

7. Goldstraw O, Chansky K, Crowley J, Rami-Porta R, Asamura H, Eberhardt WE, et al. The IASLC Lung Cancer Staging Project: Proposals for Revision of the TNM Stage Groupings in the Forthcoming (Eighth) Edition of the TNM Classification for Lung Cancer. J Thorac Oncol (2016) 11:39-51. doi: 10.1016/ j.jtho.2015.09.009

8. Tsutani Y, Miyata Y, Nakayama H, Okumura S, Adachi S, Yoshimura M, et al. Prognostic Significance of Using Solid Versus Whole Tumor Size on HighResolution Computed Tomography for Predicting Pathologic Malignant Grade of Tumors in Clinical Stage IA Lung Adenocarcionma: A Multicenter Study. J Thorac Cardiovasc Surg (2012) 143:607-12. doi: 10.1016/j.jtcvs.2011.10.037

9. Tsutani Y, Miyata Y, Mimae T, Kushitani K, Takeshima Y, Yoshimura M, et al. The Prognostic Role of Pathologic Invasive Component Size, Excluding Lepidic Growth, in Stage I Lung Adenocarcinoma. J Thorac Cardiovasc Surg (2013) 146:580-5. doi: 10.1016/j.jtcvs.2013.04.032

\section{ACKNOWLEDGMENTS}

The authors would like to thank Atsushi Kagimoto, MD, Yoshinori Handa, MD, PhD, Takashi Kumada, MD, and Takahiro Mimae, MD, PhD, for the conception and interpretation of the article. The authors would like to thank Enago (www.enago.jp) for the English language review.

\section{SUPPLEMENTARY MATERIAL}

The Supplementary Material for this article can be found online at: https://www.frontiersin.org/articles/10.3389/fonc.2021.622742/ full\#supplementary-material

Supplementary Figure 1 | Receiver operating characteristic curve of solid component size to predict recurrence. AUC, area under the curve.

10. Tsutani Y, Miyata Y, Nakayama H, Okumura S, Adachi S, Yoshimura M, et al. Solid Tumor Size on High-Resolution Computed Tomography and Maximum Standardized Uptake on Positron Emission Tomography for New Clinical T Descriptors With T1 Lung Adenocarcinoma. Ann Oncol (2013) 24:2376-81. doi: 10.1093/annonc/mdt230

11. Maeyashiki T, Suzuki K, Hattori A, Matsunaga T, Takamochi K, Oh S. The Size of Consolidation on Thin-Section Computed Tomography Is a Better Predictor of Survival Than the Maximum Tumour Dimension in Resectable Lung Cancer. Eur J Cardiothorac Surg (2013) 43:915-8. doi: 10.1093/ejcts/ ezs516

12. Murakawa T, Konoeda C, Ito T, Inoue $\mathrm{Y}$, Sano A, Nagayama K, et al. The Ground Glass Opacity Component Can Be Eliminated From T-Factor Assessment of Lung Adenocarcinoma. Eur J Cardiothorac Surg (2013) 43:925-32. doi: 10.1093/ejcts/ezs467

13. Tsutani Y, Miyata Y, Yamanaka T, Nakayama H, Okumura S, Adachi S, et al. Solid Tumors Versus Mixed Tumors With a Ground-Glass Opacity Component in Patients With Clinical Stage IA Lung Adenocarcinoma: Prognostic Comparison Using High-Resolution Computed Tomography Findings. J Thorac Cardiovasc Surg (2013) 146:17-23. doi: 10.1016/ j.jtcvs.2012.11.019

14. Hattori A, Hirayama S, Matsunaga T, Hayashi T, Takamochi K, Oh S, et al Distinct Clinicopathologic Characteristics and Prognosis Based on the Presence of Ground Glass Opacity Component in Clinical Stage IA Lung Adenocarcinoma. J Thorac Oncol (2019) 14:265-75. doi: 10.1016/ j.jtho.2018.09.026

15. Hattori A, Suzuki K, Takamochi K, Wakabayashi M, Aokage K, Saji H, et al. Prognostic Impact of a Ground-Glass Opacity Component in Clinical Stage IA non-Small Cell Lung Cancer. J Thorac Cardiovasc Surg (2020) 161:146980. doi: $10.1016 /$ j.jtcvs.2020.01.107

16. Mimae T, Tsutani $Y$, Miyata $Y$, Imai K, Ito H, Nakayama H, et al. Solid Tumor Size of $2 \mathrm{Cm}$ Divides Outcomes of Patients With Mixed Ground Glass Opacity Lung Tumors. Ann Thorac Surg (2020) 109:1530-6. doi: 10.1016/ j.athoracsur.2019.12.008

17. Kagimoto A, Tsutani Y, Mimae T, Miyata Y, Ikeda N, Ito H, et al. Preoperative Nivolumab to Evaluate Pathological Response in Patients With Stage I Non-Small Cell Lung Cancer: A Study Protocol of Phase II Trial (POTENTIAL). BMJ Open (2021) 11:e043234. doi: 10.1136/bmjopen2020-043234

18. Kagimoto A, Tsutani Y, Izaki Y, Handa Y, Mimae T, Miyata Y, et al. Prediction of Lymph Node Metastasis Using Semiquantitative Evaluation of PET for Lung Adenocarcinoma. Ann Thorac Surg (2020) 110:1036-42. doi: 10.1016/j.athoracsur.2020.03.032

19. Postmus PE, Kerr KM, Oudkerk M, Senan S, Waller DA, Vansteenkiste J, et al. Early and Locally Advanced Non-Small-Cell Lung Cancer 
(NSCLC): ESMO Clinical Practice Guidelines for Diagnosis, Treatment and Follow-Up. Ann Oncol (2017) 28(suppl 4):iv1-iv21. doi: 10.1093/ annonc/mdx 222

Conflict of Interest: The authors declare that the research was conducted in the absence of any commercial or financial relationships that could be construed as a potential conflict of interest.
Copyright (c) 2021 Tsutani, Shimada, Ito, Miyata, Ikeda, Nakayama and Okada. This is an open-access article distributed under the terms of the Creative Commons Attribution License (CC BY). The use, distribution or reproduction in other forums is permitted, provided the original author(s) and the copyright owner(s) are credited and that the original publication in this journal is cited, in accordance with accepted academic practice. No use, distribution or reproduction is permitted which does not comply with these terms. 